\title{
Knowledge, Attitudes, and Practices towards COVID-19 of Pregnant Women at a Primary Health Care Facility in South Africa
}

\author{
A. M. Hoque, A. M. Alam, M. Hoque, M. E. Hoque, and G. Van Hal
}

\section{ABSTRACT}

COVID-19 pandemic has resulted in the death of hundreds of thousands of people globally. Several preventive measures have been recommended to reduce the spread of the disease. However, the level of knowledge, attitudes, and practices (KAP) of these preventive measures among pregnant women, are yet to be evaluated in South Africa. Therefore, the objective of this study was to determine the KAP towards COVID-19 among pregnant women. The purpose was to identify KAP gaps of pregnant women and develop educational materials and implement programmes. A questionnaire-based cross-sectional study was undertaken. Student's t-test, ANOVA test, Pearson's correlation test and Binary logistic regression analysis was carried out. Majority of the respondents were single $(71 \%)$, unemployed $(52 \%)$, and had low education $(78 \%$ had either no or less than 12 years education). More than half $(51.2 \%)$ had vulnerable comorbidities for COVID-19 infection and complication. Both knowledge and attitude mean of pregnant women were found to be low at $43.5 \%$ and $30 \%$ respectively. However, their practice on prevention of COVID-19 was good at $76 \%$. Knowledge was found to be significantly positively correlated with practice towards COVID-19 $(r=0.111)$. Women having good knowledge were seven times more likely to practice positively regarding COVID-19 $(P=0.019)$. Women having 1-5 years of education were $94 \%$ less likely to practice good towards COVID-19 prevention $(\mathrm{P}=0.018)$ compared to those having post matric education. The pregnant women in this research had inadequate knowledge and attitude of COVID-19 infection. However, preventive practices were good among them. Mass education and communication strategies are thus required to improve the knowledge and attitudes of pregnant women towards COVID-19.

Keywords: Knowledge, Attitude, Practice, COVID-19, Pregnant women, South Africa.

\section{INTRODUCTION}

The coronavirus disease of 2019 known as COVID-19 has emerged as the most pressing global health issue. Since the identification of the first cases of COVID-2019 infection in Wuhan, China, in December 2019 the virus has spread to almost every country in the world and now it is a global pandemic [1]. It is evident that local transmission of COVID-19 is occurring in most countries including South Africa (SA) [2]. Early efforts have focused on describing the clinical characteristics and outcomes of COVID-19 in the general population, although current data suggests that the majority of infections with COVID-19 cause a mild form of infection [3]. However, older adults and people with comorbidities, including cardiovascular, respiratory diseases and diabetes are at increased risk of severe illness and death, with men potentially at higher risk than women [4], [5]. It is also known that pregnant women are vulnerable to infectious diseases that can cause both maternal and foetal
Published Online: January 15, 2021

ISSN: 2593-8339

DOI: $10.24018 /$ ejmed.2021.3.1.654

\section{A. M. Hoque *}

Kwadabeka Community Health Centre,

(e-mail: mhoque75@gmail.com)

A. M. Alam

Associate Professor, National Institute of Kidney Diseases and Urology, Bangladesh.

M. Hoque

South African College of Applied Psychology, Durban, South Africa.

M. E. Hoque

Management College of Southern

Africa, Durban, South Africa.

G. Van Hal

University of Antwerp, Antwerp, Belgium.

*Corresponding Author Durban, South Africa.

adverse outcomes, compared to their non-pregnant counterparts [6]. The recent reports showed that the clinical presentation of COVID-19 among pregnant women is similar to the general population with an increased risk of pregnancy and foetal adverse outcomes such as preterm delivery, foetal distress and low birth weight [7]. The reports from recent studies have found an increased incidence of neonatal pneumonia, cases of vertical transmission to the foetus, and postpartum infections to mothers and their babies [8]-[12]. Some COVID-19 related maternal deaths revealed the possibility of haemodynamic changes that pregnant mothers experience immediately after delivery [13]. Therefore, an association between the thrombogenic nature of both pregnancy and COVID- 19 is likely [14], [15]. Thus, pregnant women are considered to be a special population group because of the unique 'immune suppression' caused by pregnancy for COVID-19 infection [6]. Studies also found that the immunological and physiological changes of pregnancy might make pregnant 
women at higher risk of severe illness or mortality with COVID-19, compared with the general population [6], [16].

COVID-19 has required many countries across the globe to implement quarantine measures as the fundamental infectious disease control tool [17]. A wide fragment of world's population currently is also restricted to their homes, owing to nationwide lockdowns and homeconfinement strategies implemented in the majority of the COVID-19 hit countries including SA [17], [18]. The COVID-19 outbreak has significantly impacted on the general population of SA as there are 589886 cases (58\% being female) and 11982 deaths as of 18 August 2020 [19]. However, it is not reported how many of them are pregnant women. The National government of SA has taken commendable interventions to fight the COVID-19 pandemic based on the WHO recommendations. In addition to lockdown and home quarantine, regular hand washing with water and soap, social distancing, covering hand and mouth while coughing and avoiding touching eyes, nose and mouth are some of the initiatives [20]. The government of SA has also engaged in media campaigns to disseminate information on these preventive measures to the general population including pregnant women like many other countries. However, the level of knowledge and practice of these preventive measures against the spread of the virus among pregnant women, who constitute a vulnerable group, is yet to be evaluated.

A study undertaken and reported from a low-resource African setting found that the pregnant women (60.9\%) had adequate knowledge of the preventive measures but poor practice as $69.7 \%$ were not practicing the preventive measures against the coronavirus [21]. The determinants of poor practice of the preventive measures among the participants were mainly in the age group 31-40 years, married, grand multiparous, those residing in rural areas and having no formal education. However, there are no studies reported or known to us investigating the knowledge, attitude, and preventative practices of pregnant women in SA. Therefore, the objectives of this study were to determine the knowledge, attitude and practices of pregnant women attending a primary health care setting in Durban, South Africa.

\section{MATERIALS AND METHOD}

\section{A. Study Design}

A descriptive cross-sectional study was conducted at Kwadabeka Community Health Center (KCHC), Durban.

\section{B. Settings and Subjects}

$\mathrm{KCHC}$ is situated in the community of Kwadabeka with residence of almost 133,000 black population. Most of the residences are in formal and (mainly) informal dwellings within a boundary of approximately seven $\mathrm{km}$ radius of $\mathrm{KCHC}$. It is considered a semi-urban/rural setting. Most of these residences are reliant on public health facilities at KCHC. There are over 20,000 headcounts and of them about 400 are antenatal attendees at KCHC every month. KCHC provides a comprehensive Primary Health Care service package together with maternal services and an antenatal care package based on national guidelines [22].

\section{Sample Size}

The sample size was determined using the Epi Info 7 software. As there were no similar studies related to coronavirus disease, the calculations were based on the assumption that the probability of having good knowledge on and positive practices towards preventive measures against coronavirus disease was $50.0 \%$, at $95 \%$ confidence interval, limit of precision of $5 \%$, with a design effect of 1.0 .

\section{Participant Selection and Data Collection}

This report is a part of a bigger study that also assessed vaccine acceptance and psychological impact on pregnant women. Sample selection, data collection were reported elsewhere [23].

\section{E. Measurements}

Total knowledge, attitude and practices were measured by adding the scores for the correct (1) and incorrect (0) answers or true (1) and false (0) or positive (1) and negative (0) statements. Total score for KAP of the respondent above $50 \%$ was considered good knowledge, positive attitudes, and good practices towards COVID-19.

\section{F. Data Analysis}

Data was captured in Microsoft Excel programme, coded, and transported and analysed using SPSS version 22. Descriptive statistics such as mean with standard deviation (SD) for continuous variables and frequency distribution for categorical variables were undertaken. Student's t-test and ANOVA tests were performed to find the mean difference of the overall knowledge, attitude, and practice scores among the demographic variables. Pearson's correlation test was conducted to determine the relationship between knowledge, attitudes and practices regarding COVID-19. Binary logistic regression analysis was carried out to find the significant predictor for good practice for COVID-19 (as outcome variables) with demographic, knowledge and attitude variables using odds ratio (OR) with 95\% confidence interval (CI). P-values $<0.05$ were considered statistically significant.

\section{RESULTS}

A total of 346 pregnant women participated of which the majority were single $(71.4 \%)$ and unemployed (52\%). The demographic and obstetric information is presented in Table I. The mean age was $26.71(\mathrm{SD}=6.81)$ years and mostly $(81.2 \%)$ were between ages 20 to 39 years. More than half $(52 \%)$ were unemployed and $78 \%$ had low education of up to matric. The mean gestational age was 23.77 (SD 6.83) weeks with nearly half being primigravida (48.8\%) (Nil parity) and mean parity was $1(\mathrm{SD}=1.0)$. Half $(51.2 \%)$ of the respondents had known vulnerable comorbidities for COVID-19. Among these, the highest was HIV (28\%) followed by known hypertension $(11.3 \%)$, chronic asthma (7\%), diabetes $(3 \%)$ and $11 \%$ respondents had more than one comorbidity (not shown in table).

Figure I showed pregnant women's overall scores for knowledge, attitudes, and practices towards COVID-19. It was found that most of the participants had poor knowledge regarding COVID-19 as most of them (89\%) scored six or 
less as mean knowledge score was $4.7(\mathrm{SD}=1.58)$ out of a total of 13 points.

TABLE I: DEMOGRAPHIC AND OBSTETRICS VARIABLES OF PREGNANT

\begin{tabular}{|c|c|c|}
\hline \multicolumn{3}{|c|}{ WOMEN PARTICIPANTS } \\
\hline Variables & Frequency & Percentage \\
\hline \multicolumn{3}{|l|}{ Age $(n=346)$} \\
\hline $\begin{array}{l}<20 \text { years }(\text { Teenage } \\
\text { pregnancy) }\end{array}$ & 50 & 14.5 \\
\hline $20-29$ years & 170 & 49.1 \\
\hline 30 to 39 years & 111 & 32.1 \\
\hline 40 years and above & 13 & 3.8 \\
\hline Mean age in years (SD) & \multicolumn{2}{|c|}{$26.71(\mathrm{SD}=6.83)$} \\
\hline $\begin{array}{l}\text { Mean gestational age in } \\
\text { weeks }\end{array}$ & \multicolumn{2}{|c|}{$23.77(\mathrm{SD}=6.83)$} \\
\hline \multicolumn{3}{|l|}{$\begin{array}{l}\text { Gestational age } \\
\text { distribution }(n=346)\end{array}$} \\
\hline Up to 13 weeks & 65 & 18.8 \\
\hline 14 to 27 weeks & 169 & 48.8 \\
\hline 28 weeks and over & 112 & 32.4 \\
\hline \multicolumn{3}{|l|}{$\begin{array}{l}\text { Parity distribution } \\
(n=346)\end{array}$} \\
\hline Nil parity & 151 & 44.6 \\
\hline Parity (1-2) & 143 & 41.4 \\
\hline Parity (3 - 4) & 52 & 15.0 \\
\hline \multicolumn{3}{|l|}{ Marital status $(n=346)$} \\
\hline Single & 247 & 71.4 \\
\hline Married & 60 & 17.3 \\
\hline $\begin{array}{l}\text { Others (Living together, } \\
\text { widow) }\end{array}$ & 39 & 11.3 \\
\hline \multicolumn{3}{|l|}{ Employment } \\
\hline \multicolumn{3}{|l|}{ Status $(n=346)$} \\
\hline Full- time & 87 & 25.2 \\
\hline Part- time & 80 & 23.1 \\
\hline Unemployment & 179 & 51.7 \\
\hline \multicolumn{3}{|l|}{ Education level $(n=346)$} \\
\hline No education & 14 & 4 \\
\hline School education & 129 & 37.3 \\
\hline Matric & 126 & 36.4 \\
\hline $\begin{array}{l}\text { Post matric/ Higher } \\
\text { education }\end{array}$ & 77 & 22.3 \\
\hline Presence of co-morbidity & 177 & 51.2 \\
\hline
\end{tabular}

Regarding practice towards COVID-19, almost all (98\%) of the participants scored three or more indicating they were practicing positively as well as the mean score was 4.69 $(\mathrm{SD}=0.97)$ out of a total of six points. Three quarters of the participants had negative attitudes towards COVID-19 and the mean score was $1.77(\mathrm{SD}=1.12)$ out of a total of five points.

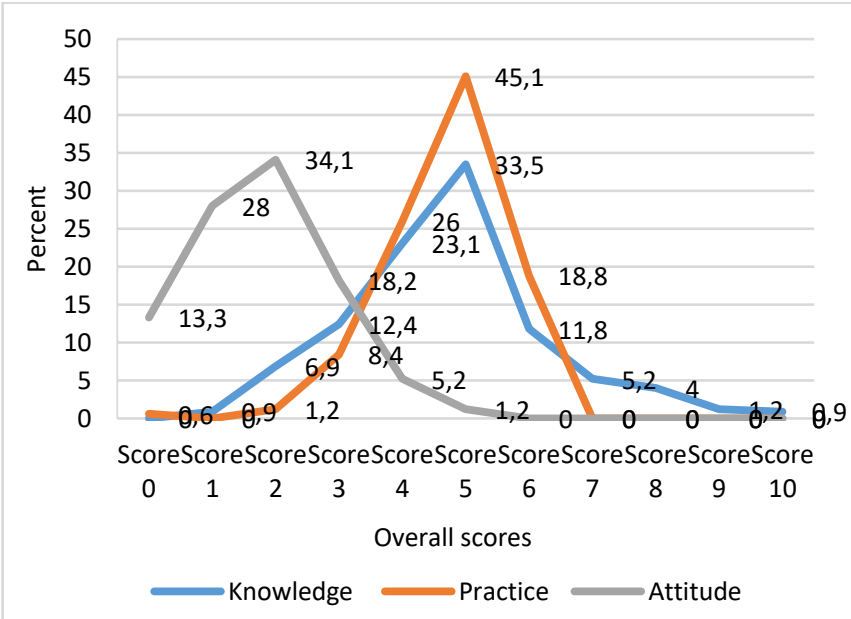

Fig. 1. Distribution of overall scores of knowledge, attitude, and practice for covid-19 among pregnant women.
Overall knowledge and practice score were found similar when compared within the demographic variables of the pregnant women $(\mathrm{p}>0,05)$ (data not shown). Women who were 13 weeks or below at their gestational age had significantly lower average attitude score ( $\mathrm{p}<0.009$ ) compared to those who were $\geq 28$ weeks of gestational age.

Pregnant women who were living together had significantly lower mean attitude score compared to single and married pregnant women $(\mathrm{p}<0.05)$ (Table II).

TABLE II: COMPARISON OF ATTITUDE SCORES WITH REGARDS TO MARITAL STATUS AND GESTATIONAL AGE OF THE RESPONDENTS USING

\begin{tabular}{|c|c|c|c|c|}
\hline & & $\mathrm{N}$ & Mean & P- Value \\
\hline \multirow[t]{3}{*}{ Gestational Age } & Up to 13 weeks & 65 & 1.446 & 0.009 \\
\hline & 14 to 27 weeks & 169 & 1.763 & \\
\hline & 28 weeks and over & 112 & 1.921 & \\
\hline \multirow[t]{3}{*}{ Marital Status } & Single & 247 & 1.830 & 0.014 \\
\hline & Married & 60 & 1.866 & \\
\hline & Living together & 39 & 1.282 & \\
\hline
\end{tabular}

Pearson correlation analysis showed that knowledge was significantly positively correlated with practice $(\mathrm{r}=0,111$, $\mathrm{p}<0,05)$ (Table III). Binary logistic regression analysis (Table IV) showed that knowledge and level of education were significantly associated with good practice towards COVID-19. It was found that having good knowledge was seven times more likely to practice positively regarding COVID-19 (OR=7.37, $\mathrm{p}=0.019$ ). Having 1-5 years of education was $94 \%$ less likely of practice positively towards COVID-19 prevention (OR=0.065, $\mathrm{p}=0.018$ ) compared to those having post matric education.

TABLE III: RESULTS FROM CORRELATION TEST ANALYSIS OF KAP AMONG THE RESPONDENTS

\begin{tabular}{ccccc}
\hline & & $\begin{array}{c}\text { Knowledge } \\
\text { score }\end{array}$ & Practice score & Attitude \\
score
\end{tabular}

TABLE IV: STEPWISE BINARY LOGISTIC REGRESSION OUTPUT FOR GOOD PRACTICE TOWARDS COVID-19

\begin{tabular}{ccccc}
\multicolumn{5}{c}{ PRACTICE TOWARDS COVID-19 } \\
\hline Variables & Sig. & $\begin{array}{c}\text { Odds Ratio } \\
\text { (OR) }\end{array}$ & \multicolumn{2}{c}{ 95\% C.I. for OR } \\
& & Lower & Upper \\
\hline Level of education & .157 & & & \\
No education & .999 & 298.46 & .000 &. \\
1-5 years schooling & .018 & .065 & .007 & .625 \\
6-11years of schooling & .582 & .614 & .108 & 3.490 \\
Matric and over & .666 & .683 & .120 & 3.872 \\
Good knowledge & .019 & 7.366 & 1.380 & 39.311 \\
Constant & .000 & 24.896 & & \\
\hline
\end{tabular}

a. Variable(s) entered on step 1: knowledge.

b. Variable(s) entered on step 2: Highest level of education.

\section{Discussion}

This study provides an insight on the level of knowledge, attitude, and preventive practice measures to deal with COVID-19 infection, transmission and preventive practices among pregnant women attending $\mathrm{KCHC}$ at the time of the COVID-19 pandemic and national lockdown in SA. To date, there has been limited published data on pregnant women's 
knowledge, attitudes, and practices toward COVID-19 in SA and globally. This study is unique because it is the first study in a PHC facility in SA to describe the knowledge, attitude, and preventive practices to protect pregnant mothers from coronavirus disease and its associated morbidity and mortality. The demographic indicators like; mean age of 26.71 year, being single $(71.4 \%)$, low level of education (half of them had less than matric education), and unemployment $(52 \%)$ status of women with pregnancy are indicative of poor socioeconomic condition.

Over half $(51.2 \%)$ of the respondents had vulnerable existing comorbidities for COVID-19. Among these, the highest comorbidity was HIV infection $(28 \%)$, followed by hypertension (11.3\%), chronic asthma (7\%) and diabetes (3\%). Limited data exists on the effect of comorbidities of pregnant women and COVID-19 infection [24]. The findings of a study that examined the effects of COVID-19 on pregnancy concluded that the presence of comorbidities does not seem to directly influence the adverse outcomes of pregnant women. However, it is observed that gestational diabetes was the most prevalent comorbidity, showing that the conditions of the fetus should be carefully evaluated as gestational diabetes may directly influence the care provided to pregnant women, exposing some of them to a worse prognosis [25]. The American College of Obstetrics and Gynecology indicates that pregnant patients with comorbidities are at increased risk for severe illness consistent with the general population with similar comorbidities [26]. Therefore, much more care be considered during antenatal period to avoid negative outcome of pregnant women.

In the absence of a COVID-19 vaccine, preventive measures play an integral role in reducing person-to-person transmission thereby controlling the spread of the disease [27]. The COVID-19 pandemic poses a major health problem to the population at large, with the mortality and morbidity being higher in the vulnerable groups which include pregnant women. Adequate knowledge is crucial in establishing a preventive knowledge and forming of positive attitudes and practices whilst inadequate knowledge poses a higher risk for infection [19], [20], [28], [29]. In this study, the level of knowledge about coronavirus disease among the participants was poor (mean knowledge 43\%), despite the government of SA having embarked on an aggressive media campaign to educate the population on the preventive measures in order to curtail the transmission of the disease. This could be attributed to the socio-demographic characteristics of the respondents, as they are from rural residence with a low educational attainment and a high level of unemployment status [21]. Education, age, and income have been documented to be highly relevant to knowledge [27].

The finding of our study on knowledge was much lower than the study conducted in other parts of Africa. Studies to assess KAP of COVID-19 in pregnant women in Nigeria attained a knowledge score of $60.9 \%$ and $78.8 \%$ among the general population in Ethiopia [21, 30]. This low level of knowledge could partly be attributed to socio-demographics of the respondents and the timing of our study as it was undertaken during the early stages of the COVID-19 epidemic in SA, where difficulty in accessing and obtaining true and timeous information was probable. Correct answers to different statements of COVID-19 knowledge ranged on both extremes. Almost all $(99 \%)$ knew one or more symptoms of COVID-19 whilst only $6.6 \%$ and $8.7 \%$ knew about the survival of the virus outside the body in air and on plastic surfaces respectively. This illustrates that the government has done commendably in the provisions made to educate the people of SA in identifying with the symptoms of coronavirus, however the findings in our study indicate that the vast majority of the study subjects had no or extremely poor knowledge on the survival of the virus. During this early stage of the pandemic in SA, enough knowledge on the symptoms of COVID-19 were readily available, but little was known to the pregnant or general population of South Africans regarding the survival of the virus.

This study illustrates that the large majority had a negative attitude (mean of 30\%) towards the COVID-19 pandemic. A few (12.9\%) of pregnant women think that they can handle well when infected with COVID-19. However, good preventive practices (mean of $76 \%$ ) are measured among these pregnant women. This could be possible because of the interventions are undertaken through regulatory measures such as lock down, social distances and use of mask at public places since the onset of the first confirmed case of the disease in SA.

Because COVID-19 is an emerging infectious disease, the optimal treatment for affected individuals has not yet been established [16], [31], [32]. Therefore, pregnant women require special attention in relation to prevention, diagnosis, and management. It is important that vulnerable populations such as pregnant women be protected from coronavirus infection. This is particularly of utmost importance especially in sub-Saharan African countries like SA.

The knowledge of the respondents was poor. However, our study found that knowledge was associated with preventive practices of COVID-19 ( $\mathrm{r}=0.111, \mathrm{p}<0.05)$. Respondents who had good knowledge are 7 times more likely to practice positively to prevent COVID-19. This correlation may be explained by a "reasoned action theory". This theory states that a person's intention to undertake a specific behaviour is a function of their knowledge and attitude towards that behaviour [33]. Similarly, respondents who had 1- 5 years of education were $94 \%$ less likely to practice positively than those who had post matric education. This study found gaps in specific aspects of knowledge, attitudes, and practices those should be emphasized in future awareness and educational campaigns.

\section{STRENGTHS AND LimitATIONS}

The strength of this study is that it is the first study to evaluate the knowledge, practice and socio-demographic variables associated with poor knowledge and practice of preventive measures against coronavirus infection among pregnant mothers in a low-resource setting. The associated factors of good practice were determined using multivariate logistic regression analysis. Despite these strengths, this study has limitations. It is a single centre study which limits the generalization of the study findings to the study area. 


\section{CONCLUSION}

In conclusion, this study showed that most of the pregnant women had inadequate knowledge and a negative attitude towards COVID-19 infection. However, the practices on preventive measures were good. Low level of educational attainment and other socio-demographic indicators were significantly associated with poor knowledge and negative attitude towards COVID-19. The implementation of national regulations for containment and prevention of transmission of COVID-19 epidemic in SA led to positive preventive practices against the infection among pregnant women in general. A multicentre study may be considered to understand the pregnant women's KAP so that the results can be generalizable for an action plan. We suggest that a community-based health education program about COVID19 could be helpful and necessary to control the disease.

\section{ABBREVIATIONS}

COVID-19: Coronavirus diseases of 2019; SA: South Africa; KAP: Knowledge, Attitude and Practice; KCHC: Kwadabeka Community Health Centre; PHC: Primary Health Care; ANOVA: Analysis of variance; SD: Standard Deviation; OR: Odds Ratio; CI: Confidence Interval.

\section{ACKNOWLEDGEMENT}

We thank all the participants who voluntarily took part in this study, the two social workers (Mrs Kholowane and Mrs Shabane) who assisted in data collection.

\section{DECLARATIONS}

Ethical consideration and consent to participate: Ethical approval was obtained from Umgungundlovu Health Ethics Research Board (reference UHERB 006/2020). Anonymity and confidentiality of the respondent was maintained at all times. Participation in the study was voluntary. The study questionnaire contained a consent section that stated the purpose, nature, objectives of the study, voluntary participation, declaration of confidentiality and anonymity. The study obtained written informed consent from the participants.

Availability of data and material: Data sets used and analysed during the current study are available from the corresponding author on reasonable request.

Competing interests: The authors declare no conflict of interest.

Funding: There was no funding for this study.

Authors' contribution: AMH - Conceptualisation, logistic regression data analysis, preparation, and finalization of the manuscript regarding pregnant women's knowledge, attitude, and practice towards the COVID-19 pandemic.

MEH - Conceptualisation, ANOVA test - data analysis and preparation of manuscript pregnant women's knowledge, attitude, and practice towards the COVID-19 pandemic.

MH, AMA- Conceptualization, data capture, demographic, Pearson correlation test- data analysis and preparation of the manuscript pregnant women's knowledge, attitude, and practice towards the COVID-19 pandemic.

GVH- Conceptualisation and finalization of the manuscript pregnant women's knowledge, attitude, and practice towards the COVID-19 pandemic.

All authors read and approved the final manuscript.

\section{REFERENCES}

[1] Zhu N, Zhang D, Wang W, et al. A novel coronavirus from patients with pneumonia in China, 2019. New Engl J Med. 2020; 382(8): 727 733.

[2] World Health Organization. Coronavirus disease 2019 (COVID-19) situation report-78. 2020. Reference Source.

[3] Zhou F, Yu T, Du R, Fan G, Liu Y, Liu Z, et al. Clinical course and risk factors for mortality of adult inpatients with COVID-19 in Wuhan, China: a retrospective cohort study. Lancet 2020; (395), 10229, 1054-62.

[4] Wu Z, McGoogan JM. Characteristics of and important lessons from the Coronavirus disease 2019 (COVID-19) outbreak in China: summary of a report of 72314 cases from the Chinese Center for Disease Control and Prevention. JAMA. 2020; 323(13):1239-42.

[5] Istituto Superiore di Sanità: Report about the Characteristics of Death Patients Positive to COVID-19 in Italy. Epidemiology for public health(Based on Data Updated on 17th March 2020).

[6] Qiao J. What are the risks of COVID-19 infection in pregnant women? The Lancet 2020;395(10226):760-762.

[7] Bouaziz J, Even M, Isnard-Bogillot F, et al. COVID-19 in pregnancy: What do we really know? Research. 2020, 9:362.

[8] Khan, S., Jun, L., Nawsherwan, Siddique, R., Li, Y., et al. Association of COVID-19 with pregnancy outcomes in health-care workers and general women. Clinical microbiology and infection. 2020; 26(6), $788-790$.

[9] Zimmermann P, Curtis N. COVID-19 in children, pregnancy and neonates: A review of epidemiologic and clinical features. Pediatr Infect Dis J 2020;39(6):469-477.

[10] Chen H, Guo J, Wang C, et al. Clinical characteristics and intrauterine vertical transmission potential of COVID-19 infection in nine pregnant women: A retrospective review of medical records. Lancet 2020;395(10226):809-815.

[11] Adebayo B. A two-day-old baby has died of Covid-19 in South Africa. $\quad 21$ May 2020. https://edition.cnn.com/2020/05/21/africa/south-africa-babydeath-coronavirus-intl/index.html (accessed 29 June 2020).

[12] Chen L, Li Q, Zheng D, et al. Clinical characteristics of pregnant women with Covid-19 in Wuhan, China. N Engl J Med 2020;385(25): 100 .

[13] Chen R, Zhang Y, Huang L, et al. Safety and efficacy of different anesthetic regimens for parturient with COVID-19 undergoing caesarean delivery: A case series of 17 patients. Can J Anaesth 2020;67(6):655- 663.

[14] Di Renzo GC, Giardina I. COVID-19 in pregnancy: Consider thromboembolic disorders and thromboprophylaxis. Am J Obstet Gynecol 2020;223(1):135.

[15] Kimberlin DW, Stagno S. Can SARS-CoV-2 infection be acquired in utero? More definitive evidence is needed. JAMA 2020;323(18):1788-1789.

[16] Ortiz EI, Herrera E, De La Torre A. Coronavirus (COVID 19) Infection in Pregnancy. Colombia Médica. RCOG, 2020;51(2).

[17] Rubin GJ, Wessely S. The psychological effects of quarantining a city. BMJ. 2020; 368.

[18] Pulla P. Covid-19: India imposes lockdown for 21 days and cases rise. BMJ, 2020; 368 (1251).

[19] Department of health, Republic of South Africa, National COVID-19 daily report. Available on https://www.nicd.ac.za/contact-us/. Accessed on 18 August 2020.

[20] World Health Organisation; Rational use of personal protective equipment (PPE) for coronavirus disease (COVID-19); Interim guidelines; 2020.

[21] Nwafor J I, Aniukwu J K, Anozie B O. Knowledge and practice of preventive measures against COVID-19 infection among pregnant women in a low-resource African setting. Int J Gynecol Obstet 2020; $1-3$.

[22] Department of Health. Guidelines for Maternity Care in South Africa: A Manual for Clinics, Community Health Centers and District Hospitals. 4th ed. Pretoria, South Africa: Department of Health; 2016.

[23] Hoque AM, Buckus S, Hoque M, Hoque ME, Van Hal G. COVID-19 Vaccine Acceptability Among Pregnant Women at a Primary Health 
Care Facility in Durban, South Africa. EJMED (accepted).

[24] Qiacheng X, Jian S, Lingling P, et al. Coronavirus disease 2019 in pregnancy. Int J Infect Disease. 2020; 95, 376-383.

[25] Lopes de Sousa AF, Carvalho HEF, Oliviera LB, et al. Effects of COVID-19 Infection during Pregnancy and Neonatal Prognosis: What Is the Evidence? Int J Environ Res Public Health. 2020;17(11):4176.

[26] Novel Coronavirus 2019. Accessed on 16 August 2020 from; https://www.acog.org/clinical/clinical-guidance/practiceadvisory/articles/2020/03/novel-coronavirus-2019. Last updated 12 August 2020.

[27] Al-Hanawi MK, Angawi K, Alshareef N, et al. Knowledge, Attitude and Practice Toward Covid-19 Among the Public in the Kingdom of Saudi Arabia; A Cross-Sectional Study. Front Public Health. 2020; 8: 217.

[28] Anikwe C. Chidebe, Ogah C.O, Anikwe I.H., Okorochukwa B.C. Coronavirus disease 2019: Knowledge, attitude, and practice of pregnant women in a tertiary hospital in Abakaliki, southeast Nigeria Inter J of Obst and Gyn. 2020; 151(2):197-202.

[29] Zhou M, Tang F, Wang Y, Nie H, Zhang L, You G, Zhang M. Knowledge, attitude and practice regarding COVID-19 among health care workers in Henan, China. Journal of Hospital Infection. 2020; 105(2): 183-87.

[30] Bekele D, Tolossa T, Tsegaye R, Teshome W. The knowledge and practice towards Covid-19 pandemic prevention among residents of Ethiopia: An Online Cross-Sectional Study. 2020. doi: https://doi.org/10.1101/2020.06.01.127381.

[31] Rasmussen SA, Smulian JC, Lednicky JA, Wen TS, Jamieson DJ. Coronavirus Disease 2019 (COVID-2019) and Pregnancy: What obstetricians need to know. AJOG. 2020.

[32] Poon LC, Yang H, Kapur A, Melamed N, et al. Global interim guidance on coronavirus disease 2019 (COVID-19) during pregnancy and puerperium from FIGO and allied partners: Information for healthcare professionals. International Journal of Gynecology \& Obstetrics. 2020;149(3):273-86.

[33] Fisher WA, Fisher JD, Rye BJ. Understanding and promoting AIDS preventive. behavior: insights from the theory of reasoned action. Health Psych. 1995;14 (255)64.

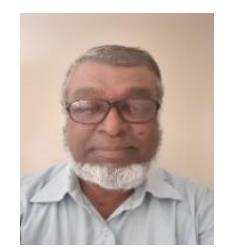

Monjurul Hoque

Kwadabeka Community Health Centre.

Durban, South Africa.

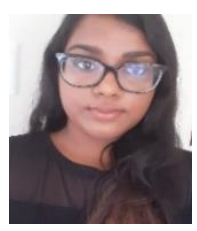

\section{Maariyah Hoque}

South African College of Applied Psychology.

Durban, South Africa.



\section{Prof. ME Hoque}

Management College of Southern Africa. 